\title{
Air Pollution Trends in Japan between 1970 and 2012 and Impact of Urban Air Pollution Countermeasures
}

\author{
Shinji Wakamatsu*, Tazuko Morikawa ${ }^{1)}$ and Akiyoshi Ito ${ }^{1)}$ \\ Atmospheric Environmental Sciences Research Laboratory (AESRL), Faculty of Agriculture, Ehime University, National University \\ Corporation, 3-5-7 Tarumi, Matsuyama, Ehime 790-8566, Japan \\ ${ }^{1)}$ Energy and Environment Research Division, Japan Automobile Research Institute (JARI), 2530 Karima, Tsukuba, Ibaraki 305-0822, \\ Japan
}

*Corresponding author. Tel: +81-89-946-9896, E-mail: wakamatu@agr.ehime-u.ac.jp

\begin{abstract}
Air pollution trends in Japan between 1970 and 2012 were analyzed, and the impact of air pollution countermeasures was evaluated. Concentrations of $\mathrm{CO}$ decreased from 1970 to 2012, and in 2012, the Japanese environmental quality standard (EQS) for $\mathrm{CO}$ was satisfied. Concentrations of $\mathrm{SO}_{2}$ dropped markedly in the 1970s, owing to use of desulfurization technologies and low-sulfur heavy oil. Major reductions in the sulfur content of diesel fuel in the $1990 \mathrm{~s}$ resulted in further decreases of $\mathrm{SO}_{2}$ levels. In 2012, the EQS for $\mathrm{SO}_{2}$ was satisfied at most air quality monitoring stations. Concentrations of $\mathrm{NO}_{2}$ decreased from 1970 to 1985 , but increased from 1985 to 1995 . After $1995, \mathrm{NO}_{2}$ concentrations decreased, especially after 2006. In 2012, the EQS for $\mathrm{NO}_{2}$ was satisfied at most air quality monitoring stations, except those alongside roads. The annual mean for the daily maximum concentrations of photochemical oxidants (OX) increased from 1980 to 2010, but after 2006, the $98^{\text {th }}$ percentile values of the OX concentrations decreased. In 2012, the EQS for OX was not satisfied at most air quality monitoring stations. Non-methane hydrocarbon (NMHC) concentrations generally decreased from 1976 to 2012. In 2011, NMHC concentrations near roads and in the general environment were nearly the same. The concentration of suspended particulate matter (SPM) generally decreased. In 2011, the EQS for SPM was satisfied at $69.2 \%$ of ambient air monitoring stations, and $72.9 \%$ of roadside air-monitoring stations. Impacts from mineral dust from continental Asia were especially pronounced in the western part of Japan in spring, and year-round variation was large. The concentration of $\mathrm{PM}_{2.5}$ generally decreased, but the EQS for $\mathrm{PM}_{2.5}$ is still not satisfied. The air pollution trends were closely synchronized with promulgation of regulations designed to limit pollutant emissions. Trans-boundary $\mathrm{OX}$ and $\mathrm{PM}_{2.5}$ has
\end{abstract}

become a big issue which contains global warming chemical species such as ozone and black carbon (so called SLCP: Short Lived Climate Pollutants). Cobeneficial reduction approach for these pollutants will be important to improve both in regional and global atmospheric environmental conditions.

Key words: Air quality standards, Air pollution trends and countermeasures, Criteria pollutants, Secondary pollutants, Volatile organic compounds, Photochemical oxidants

\section{INTRODUCTION}

Urban air pollution in Japan during the 1950s through the 2000s, and countermeasures, are described in Wakamatsu (2005).

In the 1950s, air pollution in Japan was mostly industrial pollution caused by rapid industrialization. Air pollution research in Japan in the 1950s mainly involved measuring the concentrations of air pollutants and developing strategies for coping with emissions from single-emission sources. Considerable research on atmospheric dispersion of emissions was carried out during the 1950s through the 1960s, and the first conference on air pollution research in Japan (arbitrary organization, ultimately the Japan Society for Atmospheric Environment) was held in 1959. In the 1960 s, the primary antipollution measure for a single emission source was to build a high smokestack. Although this strategy was effective in dealing with local air pollution, it had a regional environmental impact when there were multiple emission sources because high smokestacks dilute and disperse pollutants over broad areas.

The Basic Law for Environmental Pollution Control was enacted in 1967, and the Environment Agency was launched in 1971 (reorganized to Ministry of the Environment in 2001). The Japanese government esta- 
blished environmental quality standards (EQSs) and implemented laws based on them. In 1968, the Air Pollution Control Law was enacted.

In the summer of 1970, damage to humans and plants by photochemically produced air pollutants in the Tokyo metropolitan area was reported for the first time, and research on secondary air pollutants was begun. At this time, pollution from complex emission sources and urban air pollution became major issues, and it became apparent that it was necessary not only to control pollution from single- and multiple-emission sources but also to introduce measures for the integrated control of stationary and mobile sources of emissions. Regulations for the total pollution loads of $\mathrm{SO}_{\mathrm{x}}$ and $\mathrm{NO}_{\mathrm{x}}$ were implemented in 1974 and 1981, respectively. After the regulations were implemented, emissions of primary pollutants such as $\mathrm{CO}, \mathrm{SO}_{2}$, and particulate matter from stationary sources and motor vehicles dropped considerably. In contrast, the concentrations of suspended particles and secondary air pollutants such as $\mathrm{NO}_{2}$ and photochemically produced oxidants remained steady. The concentration of $\mathrm{SO}_{2}$ in the urban atmosphere decreased almost proportionally with the decrease in the sulfur content of fuel, but fuel composition has no effect on formation of NO because NO is mainly formed from atmospheric nitrogen during combustion. Moreover, NO is oxidized to $\mathrm{NO}_{2}$, and mitigating $\mathrm{NO}_{2}$ pollution is difficult.

In the 1980s, polluted areas broadened geographically, and long-range transport of photochemically produced oxidants and acid deposition became important issues.

In the 1990s, controlling $\mathrm{NO}_{\mathrm{x}}$ in urban areas became a major challenge. In 1992, the Automobile $\mathrm{NO}_{\mathrm{x}} \mathrm{Law}$ (Law Concerning Special Measures for Total Emission Reduction of Nitrogen Oxides from Automobiles in Specific Areas) was promulgated, and by the end of 2000 , measures were implemented with the goal of generally satisfying the EQS for $\mathrm{NO}_{2}$. However, results were not satisfactory, due, in part, to increased vehicle traffic.

In the 2000s, addressing worsening urban air pollution had the highest priority. In 2001, the Automobile $\mathrm{NO}_{\mathrm{x}}$ Law was amended to include possibly carcinogenic particulates from diesel exhaust, resulting in promulgation of the Automobile $\mathrm{NO}_{\mathrm{x}} / \mathrm{PM}$ Law. A variety of measures were implemented to regulate the total air pollution from automobiles in order to satisfy EQSs in certain areas by 2010 . The targeted areas included the Tokyo metropolitan area, the Osaka-Hyogo area, and the Aichi-Mie area. The basic problem involved both cutting total pollutants and creating technologies to cope with air pollution locally. To reduce outside impacts on the targeted areas, the Auto- mobile $\mathrm{NO}_{\mathrm{x}} / \mathrm{PM}$ Law was amended in 2007.

In this paper, we analyze air pollution trends in Japan between 1970 and 2012, and evaluate the impact of Japanese countermeasures against urban air pollution during that period.

\subsection{Trends in Concentrations of Criteria Air Pollutants and Related Countermeasures from 1970 to 2012}

Hourly-basis data collected at air quality monitoring stations in Japan from 1970 to 2012 were analyzed. Fig. 1 shows a map of the locations of the monitoring stations. Air quality monitoring stations in Japan are classified into three categories: ambient air pollution monitoring stations, roadside air pollution monitoring stations and acid rain monitoring stations.

Ambient air pollution monitoring stations regularly monitor the general ambient air and are located to efficiently achieve the objectives of regular monitoring: continuous recording of air quality in the same area, detection of pollutant-emitting sources, identification of areas with high concentrations of pollutants, and estimation of the effects of pollution prevention measures. The total number of ambient air pollution monitoring stations in Japan in 2011 was 1509.

Roadside air pollution monitoring stations regularly and efficiently monitor the ambient air at or near intersections, roads, and roadsides deemed to be polluted by vehicle exhaust. The total number of roadside air pollution monitoring stations in Japan in 2011 was 425 .

The acid rain monitoring stations are grasping the long range transboundary transportation and long term trend, etc. of air pollutants, such as acid rain causing substances, ozone and so on. The total number of acid rain monitoring stations in Japan in 2011 was 27.

Tables 1, 2 and 3 show the environmental quality standards, official measurement methods and environmental standard evaluations of criteria pollutants, respectively.

\subsubsection{Carbon Monoxide (CO)}

$\mathrm{CO}$ is a colorless, odorless, and poisonous gas produced from incomplete combustion of carboncontaining compounds. This highly toxic gas strongly bonds to hemoglobin, inhibiting its oxygen-carrying ability. Automobiles are the major source of anthropogenic $\mathrm{CO}$. Other sources of $\mathrm{CO}$ include woodburning stoves, incinerators, and industrial activities.

The EQS for CO was established in 1973. To satisfy the standard, the daily average for hourly values of $\mathrm{CO}$ concentrations must be $10 \mathrm{ppm}\left(12 \mathrm{mg} / \mathrm{m}^{3}\right)$ or lower, and the 8-h mean of 1-h mean $\mathrm{CO}$ concentrations must be $20 \mathrm{ppm}\left(23 \mathrm{mg} / \mathrm{m}^{3}\right)$ or lower. The 


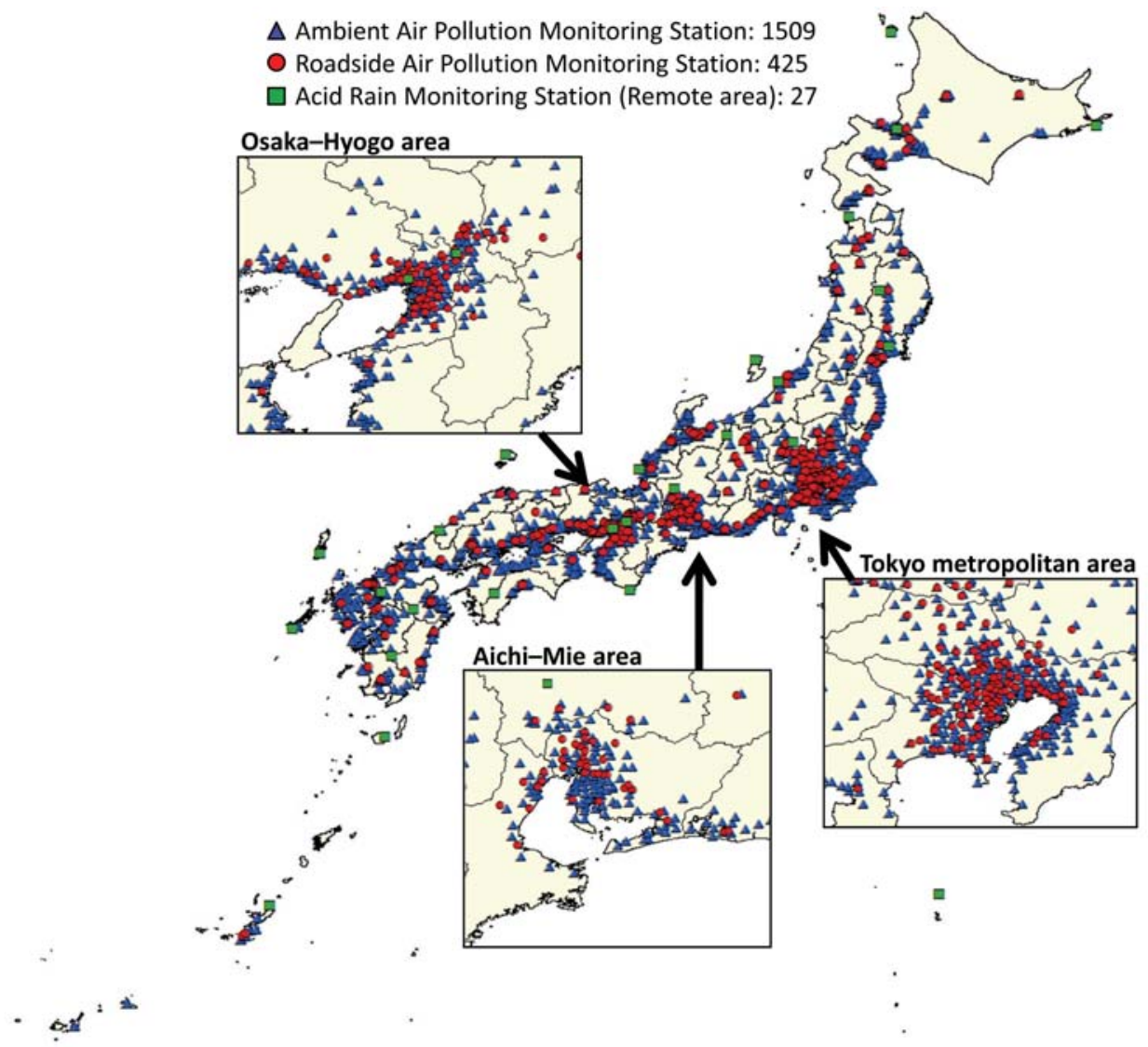

Fig. 1. Locating of air quality monitoring stations in Japan (as of 2011). Measurement item (example), $\mathrm{SO}_{2}, \mathrm{NO}_{\mathrm{x}}\left(\mathrm{NO}_{\mathrm{NO}} \mathrm{NO}_{2}\right.$ ), Oxidants, SPM, CO, NMHC (THC, $\left.\mathrm{CH}_{4}\right), \mathrm{HCl}, \mathrm{CO}_{2}, \mathrm{PM}_{2.5}$, wind speed and direction, temperature, humidity, ultraviolet, solar radiation, precipitation, traffic volume, etc.

Table 1. Environmental standards and guideline.

\begin{tabular}{|c|c|}
\hline \multicolumn{2}{|c|}{ Environmental Standards } \\
\hline $\mathrm{CO}$ & $\begin{array}{l}\text { The daily average for hourly values shall not exceed } 10 \mathrm{ppm}\left(12 \mathrm{mg} / \mathrm{m}^{3}\right) \text {, and average of hourly values for any } \\
\text { consecutive eight hour period shall not exceed } 20 \mathrm{ppm}\left(23 \mathrm{mg} / \mathrm{m}^{3}\right) .\end{array}$ \\
\hline $\mathrm{SO}_{2}$ & $\begin{array}{l}\text { The daily average for hourly values shall not exceed } 0.04 \mathrm{ppm}\left(105 \mu \mathrm{g} / \mathrm{m}^{3}\right) \text {, and hourly values shall not exceed } \\
0.1 \mathrm{ppm}\left(262 \mu \mathrm{g} / \mathrm{m}^{3}\right) \text {. }\end{array}$ \\
\hline $\mathrm{NO}_{2}$ & The daily average for hourly values shall be within the $0.04-0.06 \mathrm{ppm}\left(75-113 \mu \mathrm{g} / \mathrm{m}^{3}\right)$ zone or below that zone. \\
\hline $\mathrm{OX}$ & Hourly value should not exceed $0.06 \mathrm{ppm}\left(118 \mu \mathrm{g} / \mathrm{m}^{3}\right)$. \\
\hline SPM & The daily average for hourly values shall not exceed $0.10 \mathrm{mg} / \mathrm{m}^{3}$, and hourly values shall not exceed $0.20 \mathrm{mg} / \mathrm{m}^{3}$. \\
\hline $\mathrm{PM}_{2.5}$ & $\begin{array}{l}\text { The annual standard for } \mathrm{PM}_{2.5} \text { is less than or equal to } 15.0 \mu \mathrm{g} / \mathrm{m}^{3} \text {. The } 24 \text { hour standard is less than or equal to } \\
35 \mu \mathrm{g} / \mathrm{m}^{3} \text {. }\end{array}$ \\
\hline \multicolumn{2}{|c|}{ Environmental Guideline } \\
\hline NMHC & $\begin{array}{l}\text { Hydrocarbon levels should be determined by measuring the non-methane hydrocarbons. } \\
\text { The } 3 \text { hour ( } 6-9 \text { a.m.) average concentration should be } 0.20-0.31 \text { ppmC or less (equivalent to the value in terms } \\
\text { of ppm obtained by adding up the figures gained through the carbon molecules multiplied by the number of } \\
\text { carbon atoms per molecule). }\end{array}$ \\
\hline
\end{tabular}

trend for the annual average concentration of $\mathrm{CO}$ in air from 1970 to 2012 is shown in Fig. 2.
In 2011 and 2012, the EQS for CO was satisfied at all stations monitoring CO concentration. In 1975, 
Table 2. Official Measurement Methods.

\begin{tabular}{|c|c|}
\hline \multicolumn{2}{|c|}{ Official Measurement Methods } \\
\hline $\mathrm{CO}$ & Nondispersive infrared analyzer method (JIS B 7951). \\
\hline $\mathrm{SO}_{2}$ & Conductometric method or ultraviolet fluorescence method (JIS B 7952). \\
\hline $\mathrm{NO}_{2}$ & $\begin{array}{l}\text { (1) Colorimetry employing Saltzman reagent (with Saltzman's coefficient being 0.84). } \\
\text { (2) Chemiluminescent method using ozone. }\end{array}$ \\
\hline $\mathrm{OX}$ & $\begin{array}{l}\text { (1) Absorption spectrophotometry using a neutral potassium iodide solution. } \\
\begin{array}{ll}\text { (2) Coulometry. } & \text { (3) Ultraviolet absorption spectrometry. } \\
\text { (4) Chemiluminescent method using ethylene. } & \\
\text { (JIS B 7957) } & \end{array}\end{array}$ \\
\hline SPM & $\begin{array}{l}\text { (1) Weight concentration measuring methods based on filtration collection } \\
\text { (2) Light scattering method } \\
\begin{array}{l}\text { (4) beta-ray attenuation method that yields values having a linear relation with the values of } \\
\text { the (1)-(3) methods. }\end{array} \\
\text { (JIS B 7954) }\end{array}$ \\
\hline $\mathrm{PM}_{2.5}$ & $\begin{array}{l}\text { Mass measurement with filter sample collection which is designated as a reference method, or alternative } \\
\text { automated methods, designated as equivalent methods, which are proved to have measurement performance } \\
\text { comparable to the corresponding reference method. }\end{array}$ \\
\hline NMHC & Gas chromatography, repeated continuous measurement, peak area detection, using FID method (JIS B 7956). \\
\hline
\end{tabular}

Table 3. Environmental standard evaluation.

\begin{tabular}{|c|c|}
\hline \multicolumn{2}{|c|}{ Environmental Standard Evaluation } \\
\hline $\begin{array}{l}\mathrm{CO} \\
\mathrm{SO}_{2} \\
\mathrm{SPM}\end{array}$ & $\begin{array}{l}\text { Of the mean daily values obtained over one year, those within the top } 2 \% \text { (equivalent to the values of seven days, } \\
\text { if daily measurements are taken for } 365 \text { days) are excluded ( } 2 \% \text { exclusion value) and the highest remaining } \\
\text { values are compared with the environmental standard. If the measurement values exceed the environmental } \\
\text { standard on more than two consecutive days, they are judged as nonattainment }\end{array}$ \\
\hline $\mathrm{NO}_{2}$ & $\begin{array}{l}\text { From the mean daily values obtained over one year, those within the lower } 98^{\text {th }} \text { percentile values are selected and } \\
\text { compared with the environmental standard. }\end{array}$ \\
\hline $\mathrm{OX}$ & If the one-hour mean value exceeds $0.06 \mathrm{ppm}$, it is judged not to have attained the standard. \\
\hline $\mathrm{PM}_{2.5}$ & $\begin{array}{l}\text { The annual standard for } \mathrm{PM}_{2.5} \text { is less than or equal to } 15.0 \mu \mathrm{g} / \mathrm{m}^{3} \text {. The } 24 \text { hour standard, which means the annual } \\
98^{\text {th }} \text { percentile values at designated monitoring sites in an area, is less than or equal to } 35 \mu \mathrm{g} / \mathrm{m}^{3} \text {. }\end{array}$ \\
\hline
\end{tabular}

the average $\mathrm{CO}$ concentrations at roadside stations were almost double those at ambient air-monitoring stations, but in 2011, the CO concentrations at the roadside and ambient air-monitoring stations were almost the same.

\subsubsection{Sulfur Dioxide $\left(\mathrm{SO}_{2}\right)$}

Combustion of fossil fuels is a major source of $\mathrm{SO}_{2}$. Sources of ambient $\mathrm{SO}_{2}$ include stationary sources (coal and oil combustion sites, for example, power plants, steel mills, oil refineries, nonferrous smelters, and pulp and paper mills) and mobile sources. $\mathrm{SO}_{2}$ not only affects human respiratory organs, but also is a primary contributor to acid deposition (acid rain and dry deposition) and secondary aerosols.

The EQS for $\mathrm{SO}_{2}$ was established in 1973. To satisfy the standard, the daily average for hourly values of
$\mathrm{SO}_{2}$ concentrations must be $0.04 \mathrm{ppm}\left(105 \mu \mathrm{g} / \mathrm{m}^{3}\right)$ or lower, and the 1-h mean $\mathrm{SO}_{2}$ concentration must be $0.1 \mathrm{ppm}\left(262 \mu \mathrm{g} / \mathrm{m}^{3}\right)$ or lower. The trend for the annual average concentration of $\mathrm{SO}_{2}$ in air from 1970 to 2012 is shown in Fig. 2.

In the 1970s, the $\mathrm{SO}_{2}$ concentrations along roads and in the general environment dropped markedly. $\mathrm{SO}_{2}$ emissions from stationary sources decreased owing to the use of desulfurization technologies and low-sulfur heavy oil. In the past, $\mathrm{SO}_{2}$ from mobile sources has mainly been due to sulfur in diesel fuel, but refiners have reduced the sulfur content in diesel fuel on several occasions, and the $\mathrm{SO}_{2}$ concentrations along roads and in the general environment have declined as a result. In 2011 and 2012, the EQS was satisfied at most stations monitoring $\mathrm{SO}_{2}$ concentrations. Occasionally, the concentration of atmos- 

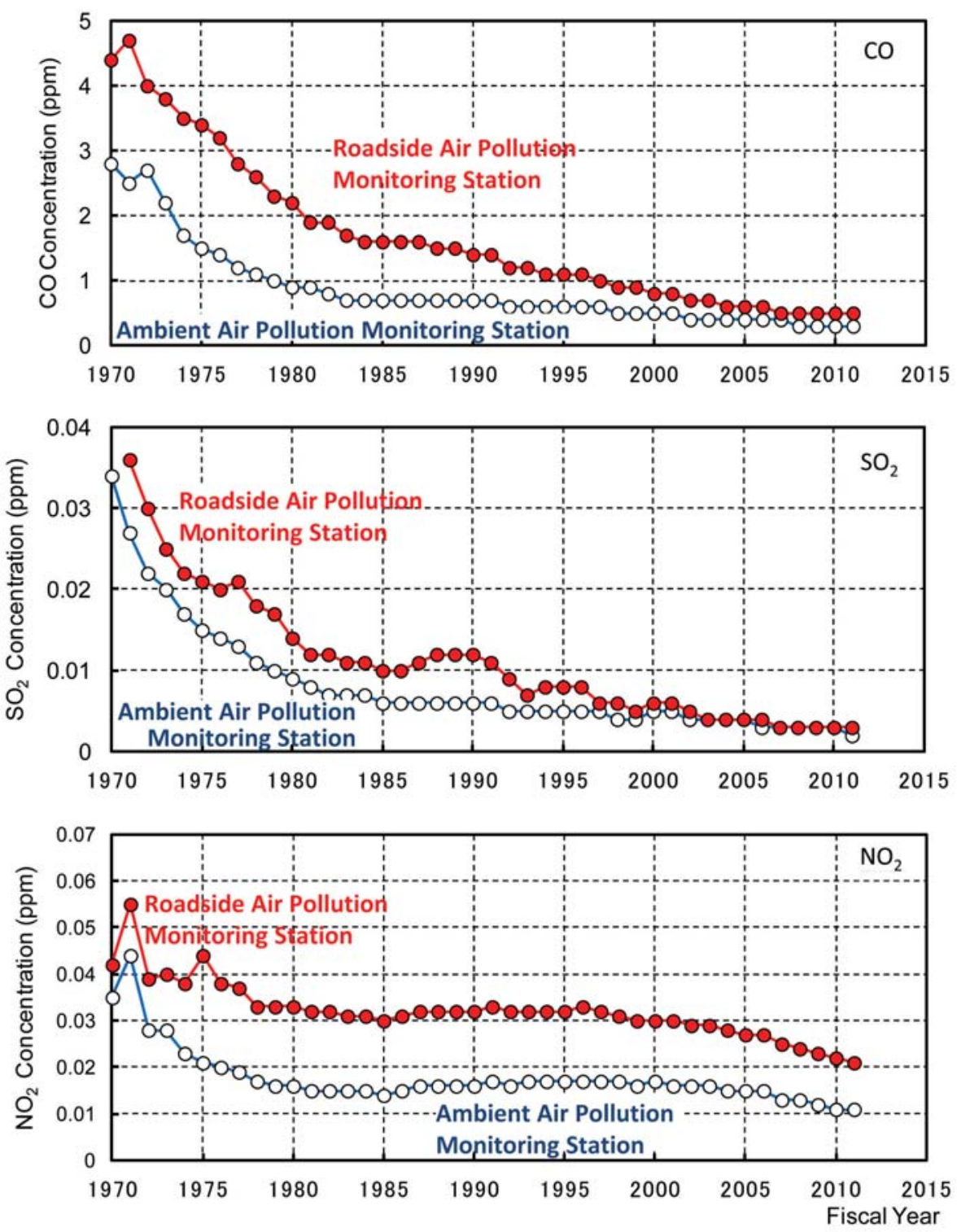

Fig. 2. Annual average concentrations of $\mathrm{CO}, \mathrm{SO}_{2}$, and $\mathrm{NO}_{2}(1970-2012)$.

pheric $\mathrm{SO}_{2}$ increased, mainly due to emission of $\mathrm{SO}_{2}$ from volcanoes.

\section{1.3 Nitrogen Dioxide $\left(\mathrm{NO}_{2}\right)$}

$\mathrm{NO}_{2}$ is a highly reactive gas and an important precursor to $\mathrm{O}_{3}$, secondary aerosols, and acid deposition. At high concentrations, $\mathrm{NO}_{2}$ affects human respiratory organs. Most $\mathrm{NO}_{2}$ arises from combustion of fuel. Gasoline-fueled vehicles $(\mathrm{GV})$ and diesel-fueled vehicles (DV) and stationary sources such as electric and industrial boilers are major sources of $\mathrm{NO}_{2}$ emission.

The EQS for $\mathrm{NO}_{2}$ was established in 1973 and re- vised in 1978 . To satisfy the standard, the daily average for hourly values of $\mathrm{NO}_{2}$ concentrations must be 0.04-0.06 ppm $\left(75-113 \mu \mathrm{g} / \mathrm{m}^{3}\right)$ or lower. The trend for the annual average concentration of $\mathrm{NO}_{2}$ in air from 1970 to 2012 is shown in Fig. 2.

Atmospheric $\mathrm{NO}_{2}$ concentrations decreased from 1970 to 1985 , but increased from 1985 to 1995 . After $1995, \mathrm{NO}_{2}$ levels decreased, especially after 2006, when they dropped remarkably. $\mathrm{NO}_{2}$ concentrations at roadside air-monitoring stations were notably higher than those at ambient air-monitoring stations from 1970 to 2012 (Fig. 2), mainly due to the short lifetime of $\mathrm{NO}_{2}$ in the atmosphere. 

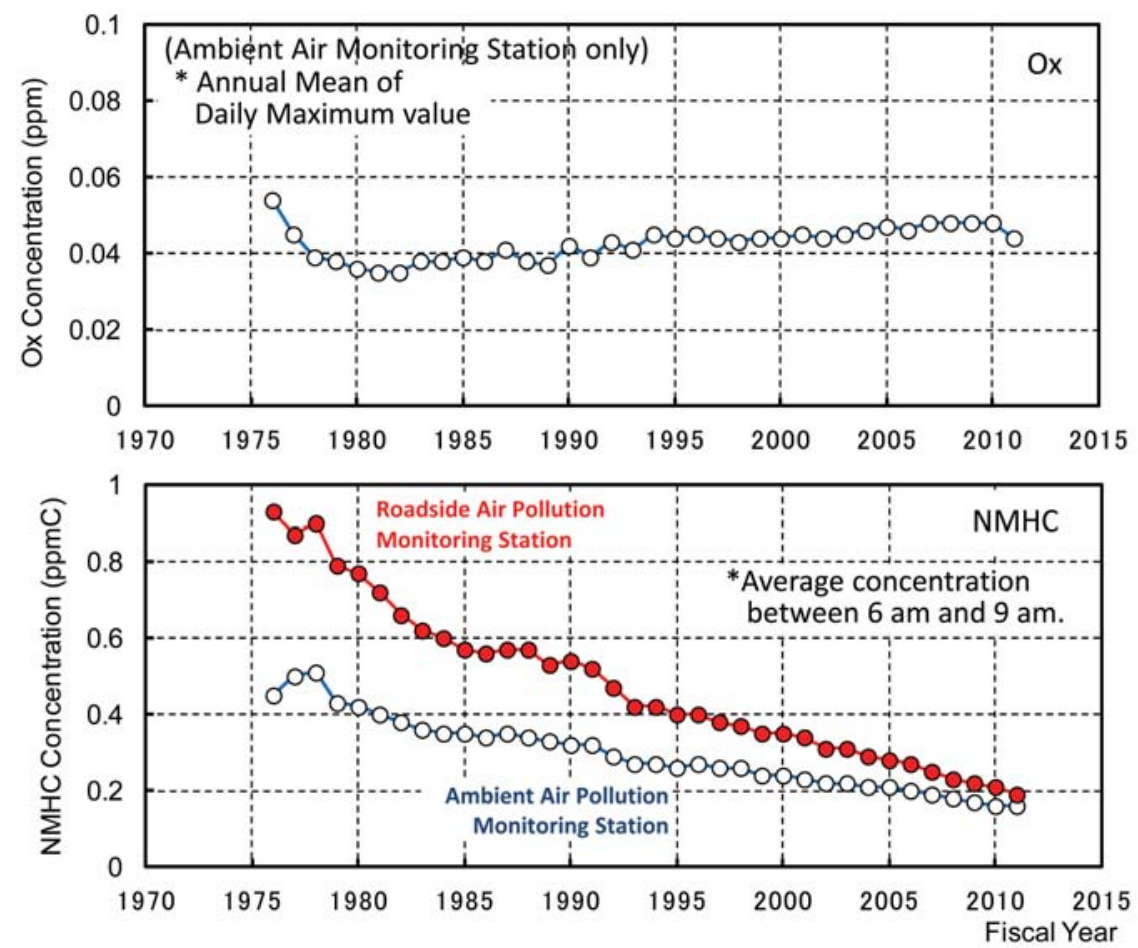

Fig. 3. Annual average of daily maximum concentrations of Ox (1976-2012) and annual average concentrations of NMHC between 6 am and 9 am(1976-2012).

In 2011 and 2012, the EQS was satisfied at most stations monitoring $\mathrm{NO}_{2}$ concentrations, except roadside stations.

The atmospheric concentrations of the primary air pollutants, $\mathrm{SO}_{2}$ and $\mathrm{CO}$, have declined owing to emission-control technologies, but $\mathrm{NO}_{2}$ is harder to control because it is produced during the combustion process and forms secondary products in the atmosphere. An especially difficult challenge is holding down emissions from diesel-powered, heavy-duty vehicles.

Owing to the $\mathrm{NO}_{\mathrm{x}} / \mathrm{PM}$ Law, the concentrations of $\mathrm{NO}_{2}$ in the Tokyo metropolitan area, the Osaka-Hyogo area, and the Aichi-Mie area have fallen in recent years.

\section{1.4 Photochemical Oxidants (OX)}

Photochemical oxidants are secondary air pollutants. Although $\mathrm{O}_{3}$ in the stratosphere shields the Earth from harmful ultraviolet radiation from the sun, a high concentration of $\mathrm{O}_{3}$ at ground level is a major health and environmental concern. High concentrations of $\mathrm{O}_{3}$ irritate mucous membranes, affect respiratory organs, damage plants, and reduce agricultural harvests. In the United States, studies on the adverse effect of high concentrations of ground-level $\mathrm{O}_{3}$ on human health began to emerge around 1945. In Japan, the first report of health damage attributable to OX in the Tokyo me- tropolitan area appeared in 1970 . Ozone is a major component of OX in the urban atmosphere.

The EQS for OX was established in 1973. To satisfy the standard, the 1-h mean OX concentration must be $0.06 \mathrm{ppm}\left(0.118 \mu \mathrm{g} / \mathrm{m}^{3}\right)$ or lower. The trend for the annual average of the daily maximum OX concentrations from 1976 to 2012 is shown in Fig. 3. From 1980 to 2010 , the annual mean of the daily maximum OX concentrations increased. In 2011 and 2012, the EQS was not satisfied at most stations monitoring OX concentrations.

\subsubsection{Non-methane Hydrocarbons (NMHC)}

Volatile organic compounds (VOCs) undergo complex photochemical reactions with $\mathrm{NO}_{\mathrm{x}}$ to form $\mathrm{OX}$. These reactions are stimulated by sunlight and temperature, and peak OX levels typically occur during warm times of the year. Additionally, secondary aerosols may be formed in photochemical reactions involving VOCs. VOCs are emitted from both anthropogenic and biogenic sources. There are more than 100 kinds of VOCs in ambient air.

Guidelines for VOC levels in the atmosphere were established in 1976. GC-FID (gas chromatography with flame ionization detection) measurements of the total amount of atmospheric NMHC have been carri- 
ed out in Japan since 1976, and VOC levels in the atmosphere should be reflected in those measurements. To satisfy the NMHC guideline, the 3-h (6-9 am) average NMHC concentration should be 0.20 $0.31 \mathrm{ppmC}$ or lower.

The trend for the annual average concentration of NMHC in air between 6 am and 9 am for the period 1976-2012 is shown in Fig. 3. NMHC concentrations have been decreasing since 1978. In 2011, NMHC concentrations at roadside air-monitoring stations were almost the same as those at ambient air-monitoring stations.

\section{1. 6 Particulate Matter (PM)}

Particulate matter refers to dust, dirt, soot, smoke, and liquid droplets emitted into the air. Sources of PM include factories, power plants, cars, construction activities, fires, and natural windblown dust. Most PM arises from combustion of fossil fuel. In large urban areas, PM includes substantial amounts of secondary particles. Secondary particles are formed in the atmosphere by condensation or by the transformation of emitted gaseous pollutants. PM has a long residence time in the atmosphere, and at high concentrations, PM affects respiratory organs by adhering to the lungs and trachea.

Suspended particulate matter (SPM) is defined as airborne particles with aerodynamic diameters less than or equal to $10 \mu \mathrm{m}$.

The EQS for SPM was first established in 1973. To satisfy the standard, the daily mean of 1-h SPM concentrations must be less than or equal to $0.10 \mathrm{mg} / \mathrm{m}^{3}$, and the 1-h mean SPM concentration must be less than $0.20 \mathrm{mg} / \mathrm{m}^{3}$.

Research on the effects of particles with aerodynamic diameters less than or equal to $2.5 \mu \mathrm{m}\left(\mathrm{PM}_{2.5}\right)$ has been vigorously conducted in the United States. In Japan, the EQS for $\mathrm{PM}_{2.5}$ was established in 2009. The annual standard for $\mathrm{PM}_{2.5}$ is less than or equal to $15.0 \mu \mathrm{g} / \mathrm{m}^{3}$, and the $24-\mathrm{h}$ standard is less than or equal to $35 \mu \mathrm{g} / \mathrm{m}^{3}$.

The US EPA defines $\mathrm{PM}_{10}$ and $\mathrm{PM}_{2.5}$ as particulate matter with aerodynamic diameters of 10 and $2.5 \mu \mathrm{m}$ collected with $50 \%$ efficiency by $\mathrm{PM}_{10}$ and $\mathrm{PM}_{2.5}$ sampling devices, respectively. Because of differences in particle-size cutoff characteristics during measurement, SPM is not the same as $\mathrm{PM}_{10}$. SPM particles are collected with $100 \%$ efficiency at the $10-\mu \mathrm{m}$ cut point of aerodynamic diameter, whereas they are collected with $50 \%$ efficiency at the $7 \mu \mathrm{m}$ cut point. On the $\mathrm{PM}_{10}$ scale, Japan's SPM is about $\mathrm{PM}_{7} . \mathrm{PM}_{2.5}$, SPM, and $\mathrm{PM}_{10}$ are defined in Fig. 4.

The annual average SPM concentration in the environment has been generally decreasing since 1975

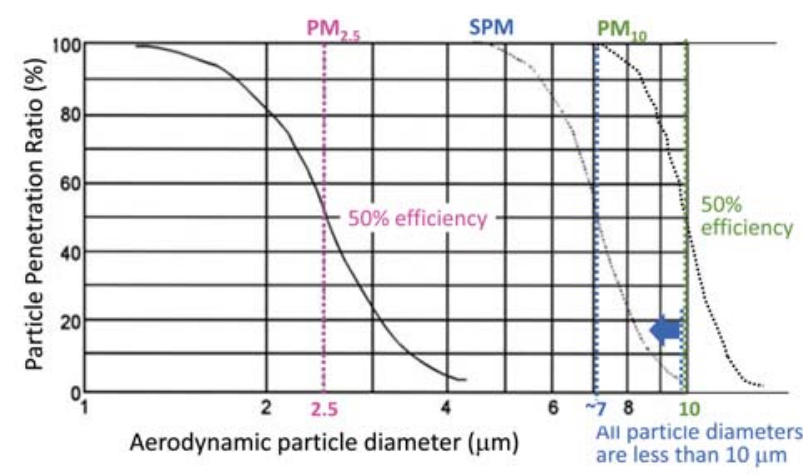

Fig. 4. Definitions of $\mathrm{PM}_{2.5}$, SPM and $\mathrm{PM}_{10}$. SPM (Suspended particulate matter) is defined as airborne particles with a diameter smaller than or equal to $10 \mu \mathrm{m}$. The U.S. EPA defines $\mathrm{PM}_{10}\left(\mathrm{PM}_{2.5}\right)$ as particulate matter with a diameter of 10 (2.5) micrometers collected with $50 \%$ efficiency by a $\mathrm{PM}_{10}$ $\left(\mathrm{PM}_{2.5}\right)$ sampling collection device.

(Fig. 5). In 2011, the EQS was satisfied at $69.2 \%$ of ambient air-monitoring stations, and $72.9 \%$ of roadside air-monitoring stations. Attainment criteria for SPM environmental standards are as follows.

1. Of the mean daily values obtained over one year, those within the top $2 \%$ (equivalent to values for 7 days, if daily measurements are made for 365 days) are excluded ( $2 \%$ exclusion value), and the highest remaining values are compared with the environmental standard.

2. If the mean daily values exceed the environmental standard on more than two consecutive days, they are "nonattainment values".

Mineral dust from continental Asia often affects wide-area SPM air pollution in Japan. The impacts are especially pronounced in the western part of Japan in the spring, and year-round variation is large.

The trend for the annual average $\mathrm{PM}_{2.5}$ concentrations at four monitoring stations in Tokyo is shown in Fig. 5. The environmental concentration of $\mathrm{PM}_{2.5}$ has fallen in recent years, but still exceeds the EQS.

\section{2 Air Pollution Trends in the Tokyo Metropolitan Area (TMA) and Countermeasures}

\subsubsection{Impact of Regulations on Levels of $\mathrm{CO}, \mathrm{SO}_{2}$, and $\mathrm{NO}_{2}$ in Air}

Automobiles are a major source of $\mathrm{CO}$ in the Tokyo metropolitan area. Fig. 6 shows the distribution of air quality monitoring stations in Tokyo for the year 2011. The history and impact of regulations focused on reducing $\mathrm{CO}$ emissions from automobiles in Tokyo from 1973 to 2012 are shown in Fig. 7. 

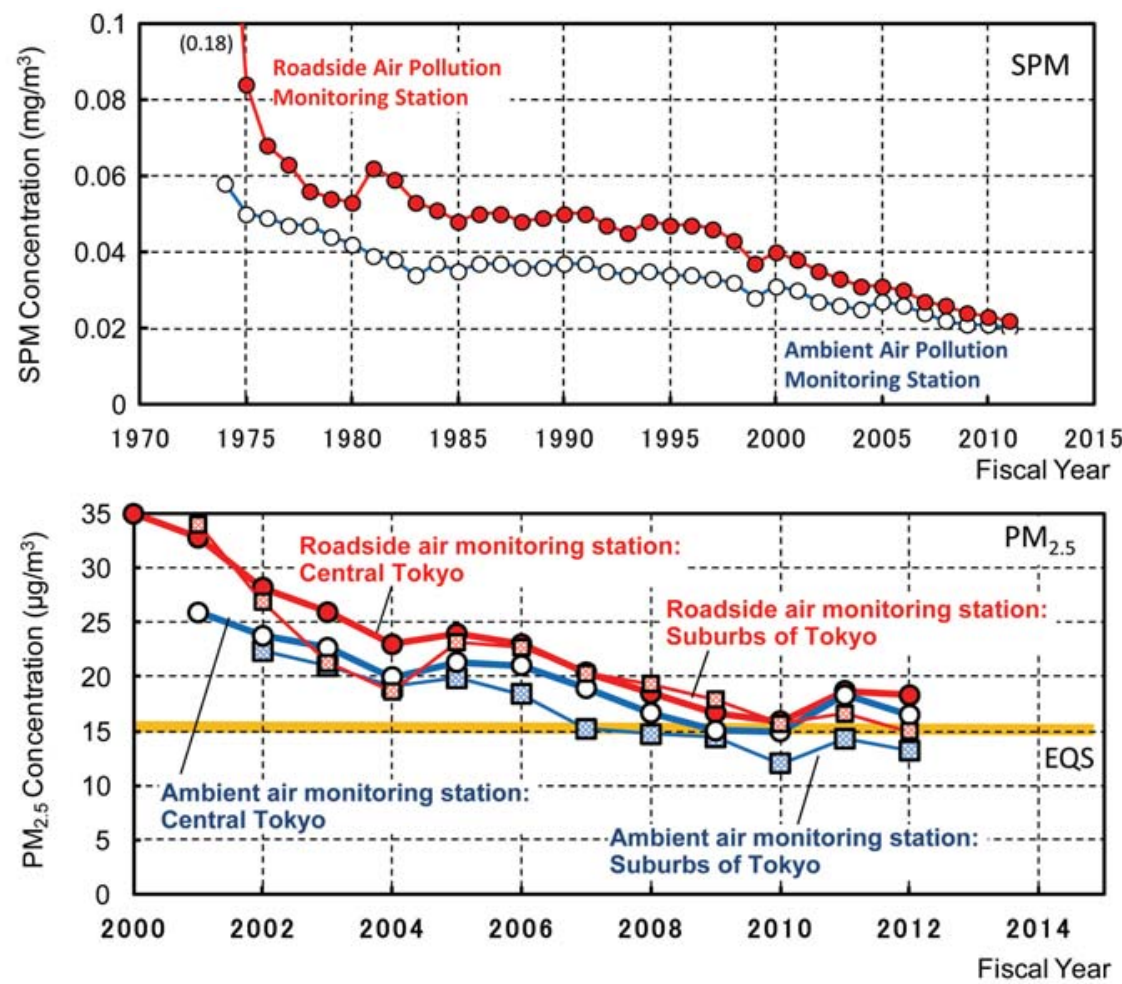

Fig. 5. Annual average concentrations of SPM (1975-2012) and annual average concentrations of $\mathrm{PM}_{2.5}$ at four stations in Tokyo (2000-2012).

\begin{tabular}{|c|c|}
\hline \multicolumn{1}{|c|}{} & $\begin{array}{c}\text { \# of Ambient air - } \\
\text { monitoring stations }\end{array}$ \\
\hline Tokyo & 48 \\
\hline Japan & 1509 \\
\hline & $\begin{array}{c}\text { \# of Roadside air - } \\
\text { monitoring stations }\end{array}$ \\
\hline Tokyo & 40 \\
\hline Japan & 425 \\
\hline
\end{tabular}

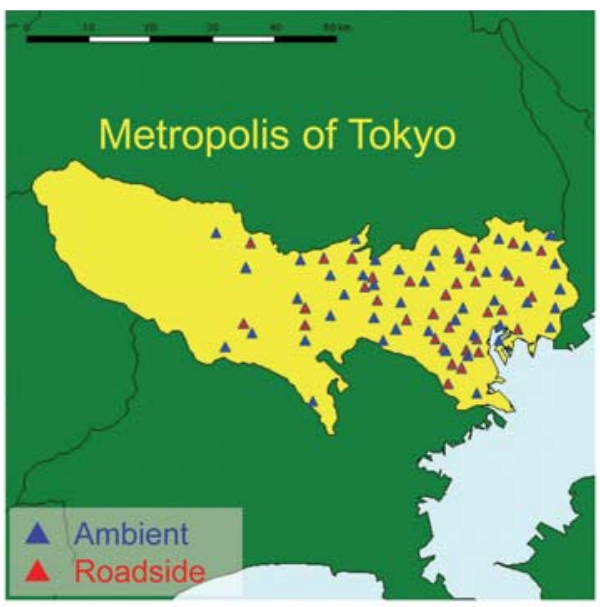

Fig. 6. Distribution of air quality monitoring stations in Tokyo.

In the Tokyo metropolitan area, sulfur in diesel fuel is a major source of $\mathrm{SO}_{2}$ emissions. Since the 1990s, the sulfur content in diesel fuels in Japan has been reduced in several steps, as follows:

- $0.2 \%$ (2000 ppm) S limit beginning in 1992

$\cdot 0.05 \%$ (500 ppm) S limit beginning in 1997
- mandatory 50-ppm S limit beginning in 2005; in practice, 50-ppm $\mathrm{S}$ diesel fuel was introduced nationwide in April 2003 through a voluntary effort of the Japanese petroleum industry

- 10-ppm S limit since 2007; the Japanese petroleum industry made a voluntary commitment to supply 10-ppm S fuel in January 2005 (nationwide, with 


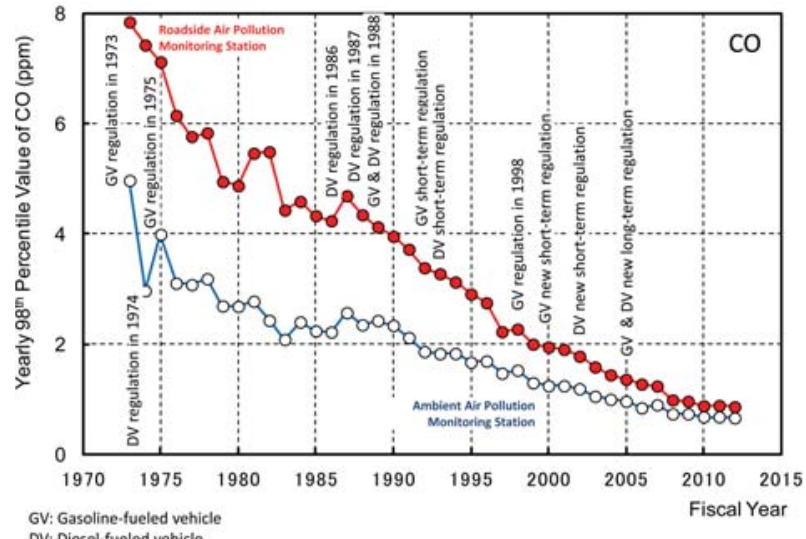

DV: Diesel-fueled vehicle

Fig. 7. History and impact of regulations focused on reducing $\mathrm{CO}$ emissions from automobiles in Tokyo. Trends for the yearly $98^{\text {th }}$ percentile values of the $\mathrm{CO}$ concentrations are shown.

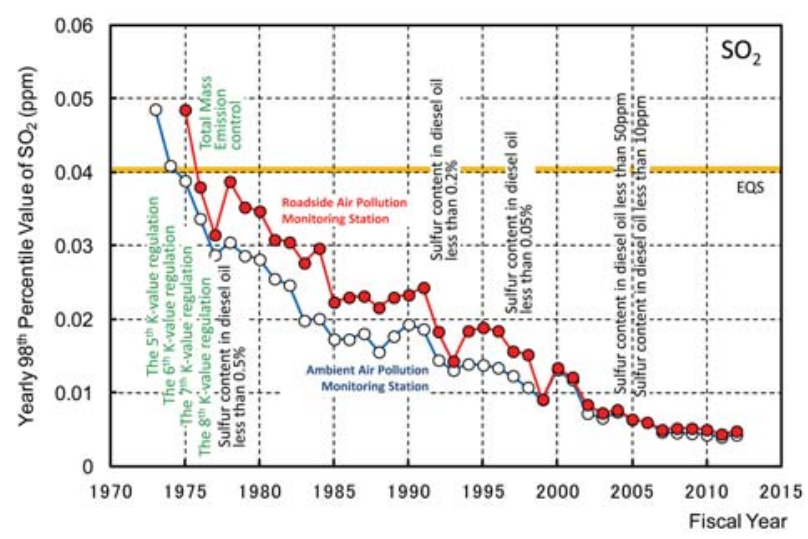

Fig. 8. History and impact of regulations focused on reducing $\mathrm{SO}_{2}$ levels in Tokyo. Trends for the yearly $98^{\text {th }}$ percentile values of the $\mathrm{SO}_{2}$ concentrations are shown.

the exception of certain island areas and Okinawa Prefecture)

The history of these reductions and their impact on $\mathrm{SO}_{2}$ levels, together with the history and impact of regulations focused on reducing $\mathrm{SO}_{2}$ emissions from factories and business sites during the 1970s, are shown in Fig. 8.

All air-monitoring stations recorded decreases in environmental $\mathrm{SO}_{2}$ concentrations corresponding to the stepwise reductions of sulfur in diesel fuel. Since 1999 , the $\mathrm{SO}_{2}$ concentrations recorded at roadside air-monitoring stations have been nearly identical to those recorded at ambient air-monitoring stations.

The history and impact of regulations reducing $\mathrm{NO}_{2}$ emissions in Tokyo are shown in Fig. 9. The environmental concentration of $\mathrm{NO}_{2}$ decreased slightly from

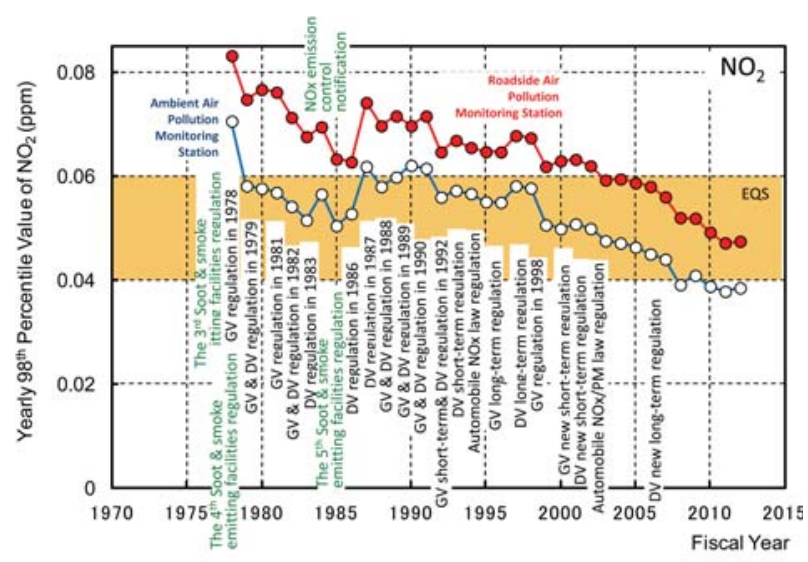

Fig. 9. History and impact of regulations focused on reducing $\mathrm{NO}_{2}$ levels in Tokyo. Trends For the yearly $98^{\text {th }}$ percentile values of the $\mathrm{NO}_{2}$ concentrations are shown.

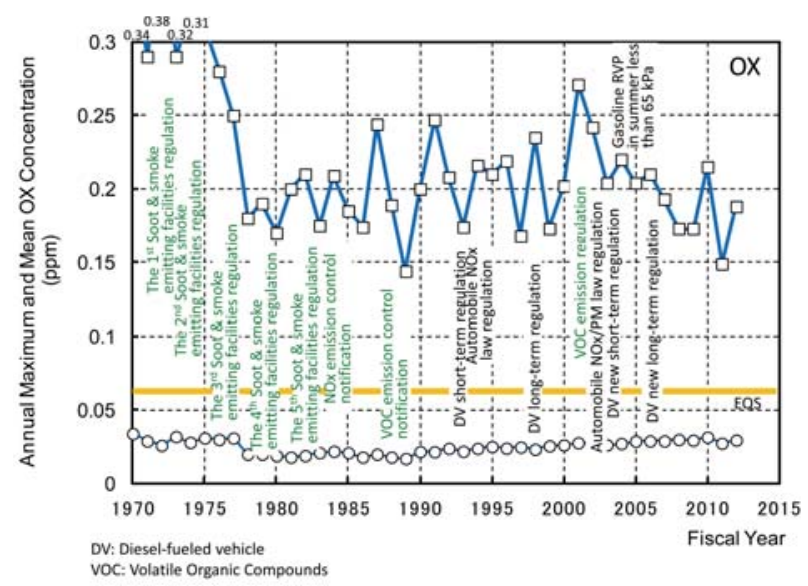

Fig. 10. History and impact of regulations focused on reducing OX levels in Tokyo.

1985 to 2000. This tendency is different from the trend for all of Japan over the same period (Fig. 2). The environmental concentration of $\mathrm{NO}_{2}$ decreased sharply after promulgation of the Automobile $\mathrm{NO}_{\mathrm{x}} / \mathrm{PM}$ Law in 2001 .

\subsubsection{Impact of Regulations on Level of OX in Air}

The history and impact of regulations focused on reducing OX levels in Tokyo are shown in Fig. 10. From 1978 to 2000, the annual maximum OX concentration in Tokyo showed an increasing trend. After VOC regulations were introduced in 2006, the annual maximum OX concentration in Tokyo decreased. In contrast, the annual mean concentration of OX increased slightly from 1978 to 2010.

VOCs are photochemically oxidized to OX pollutants in the atmosphere, and some VOCs can adversely 


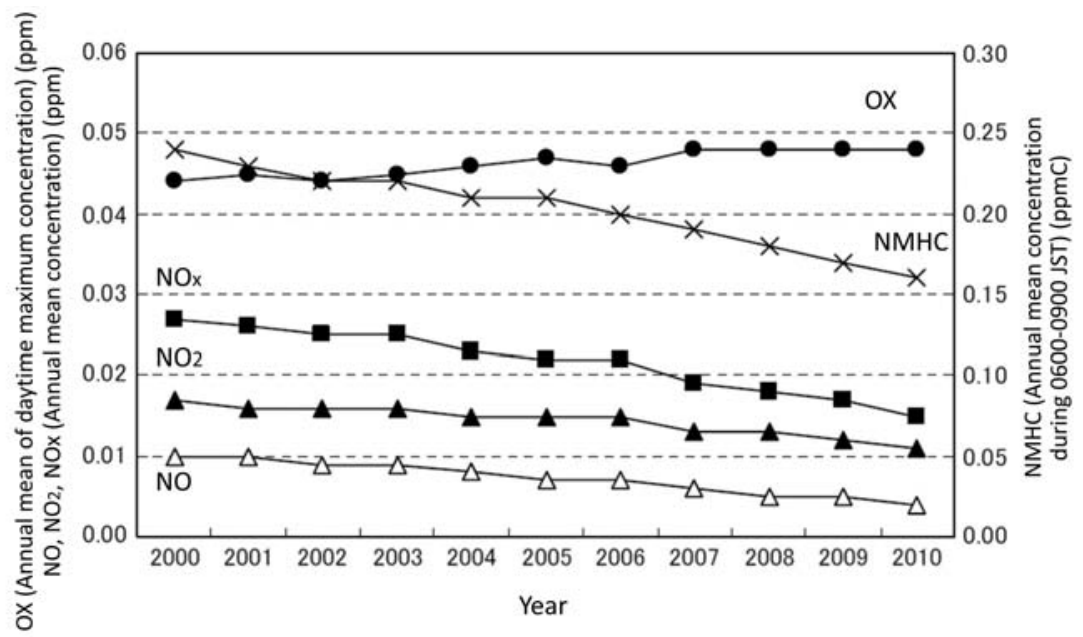

Fig. 11. Trends for annual mean concentrations of $\mathrm{NO}, \mathrm{NO}_{2}, \mathrm{NO}_{\mathrm{x}}, \mathrm{OX}$, and $\mathrm{NMHC}$ in Japan (MOE, 2012).

affect human health. Anthropogenic sources of VOCs include automobiles, chemical industries, dry cleaners, paint shops, and businesses using organic solvents. For benzene and other hazardous VOCs, annual averages are used for EQSs, because long-term exposure to such VOCs can be harmful.

Japan has routinely implemented measures to control VOCs from mobile sources, but measures to control VOCs from stationary sources have been implemented only recently. Measures aimed at stationary sources were launched in April 2006 under the Air Pollution Control Law as amended in May 2004.

VOCs can form ozone to varying degrees, depending on their components, and therefore emphasis is usually placed on highly reactive components. However, the approach depends on what measure is used to assess ambient ozone concentration. If a highly localized concentration is the issue, high reactivity is singularly important, but if the concentration over a broad area is the issue, substances with low reactivity can make a significant contribution and are also important. The aim should be an overall reduction in the mathematical product of the reactivity and the abundance of VOC components. From this perspective, initiatives for the overall reduction of hydrocarbons have been proposed to reduce VOCs in the environment.

The idea of maximum incremental reactivity (MIR, the ozone-forming potential of a VOC component per unit weight) was used to decide which substances to regulate. The ozone-forming potentials of the individual VOC components were assessed by using a simulation model. In view of Japan's VOC sources and meteorological conditions, VOC components with ozone-forming potentials lower than the ozone-forming potential of methane were exempted from regula- tion.

Controlling VOC emissions is primarily meant to prevent secondary air pollution, and many small- and medium-size enterprises (for example, paint shops) have traditionally controlled their hydrocarbon emissions as a way of limiting foul odors. At plating shops, dichloromethane, trichloroethylene, and other chlorinated organic solvents have been widely used for degreasing and finishing. These hazardous chemicals have primarily been controlled through strict environmental regulations.

The newest regulations for controlling VOC emissions were the first regulations to incorporate the idea of a "best mix" of legal regulations and voluntary cuts by businesses. Many experts from industry participated in discussions on the specific provisions of the regulations, which was a first for the environmental policy-making process in Japan. The goal was a $30 \%$ reduction of the emissions in $2000(1,850,000$ tons; $1,420,000$ tons from stationary sources) by 2010 .

In 2005 and 2009, VOC emissions from stationary sources were $1,110,000$ tons and 820,000 tons, respectively. A reduction of more than $42 \%$ in VOC emissions from stationary sources in Japan was achieved from 2000 to 2009.

Fig. 11 shows trends for the annual mean concentrations of $\mathrm{NO}, \mathrm{NO}_{2}, \mathrm{NO}_{\mathrm{x}}, \mathrm{OX}$, and $\mathrm{NMHC}$ in Japan. In recent years, the annual mean concentrations of $\mathrm{NO}, \mathrm{NO}_{2}, \mathrm{NO}_{\mathrm{x}}$, and $\mathrm{NMHC}$ have been decreasing, whereas the annual mean concentration of $\mathrm{OX}$ has been increasing.

Formation of OX is highly dependent on meteorological factors such as temperature, total solar radiation, and wind speed. Wakamatsu et al. (1996) found a linear relationship between daily maximum temperature 


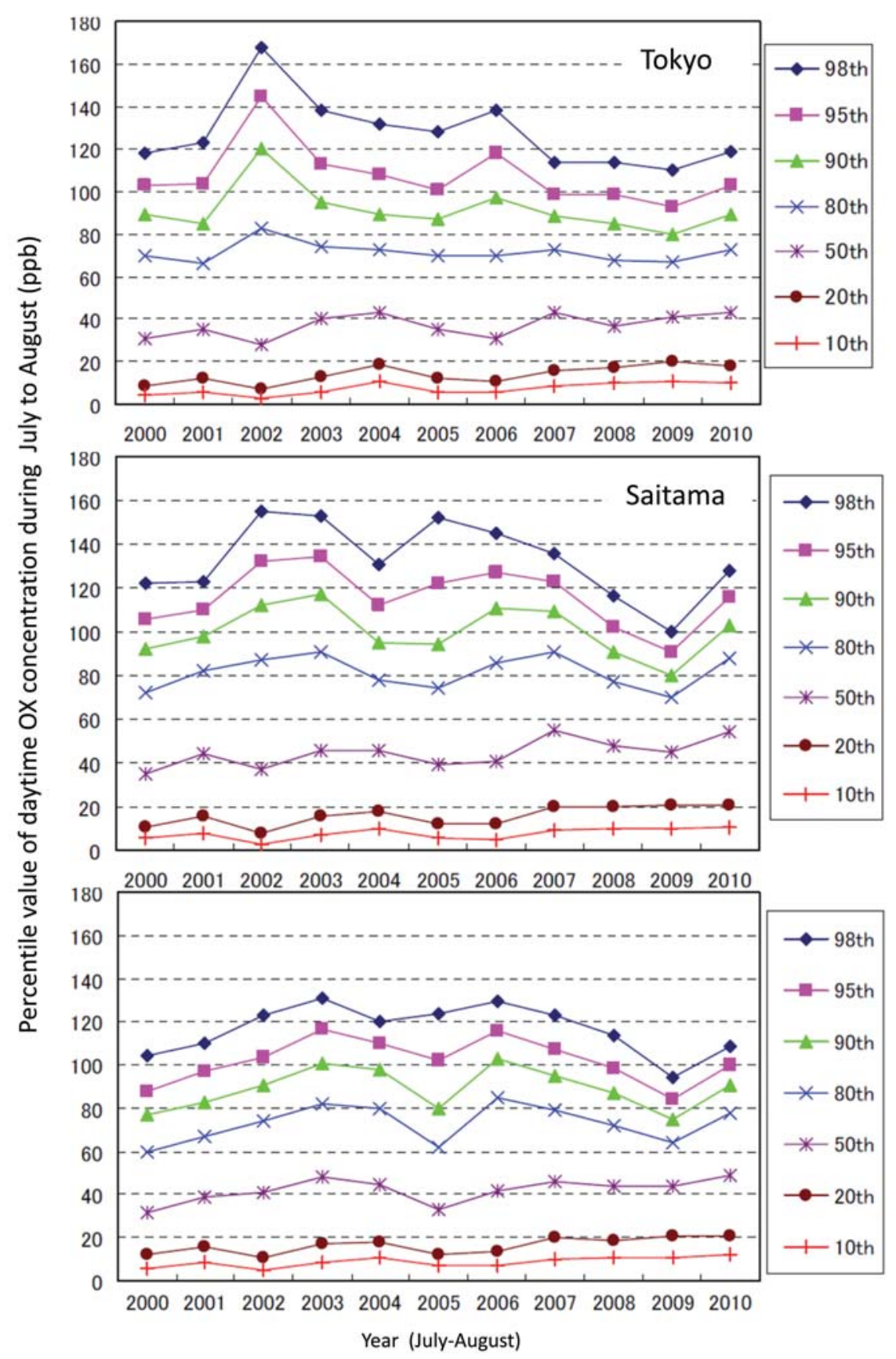

Fig. 12. Percentile values for OX concentrations in theTMA (metropolis of Tokyo, Saitama, Gumma,and Tochigi Prefecture) from 2000 to 2010. Daily data for each year were selected underthe following fixed ranges to eliminatemeteorological bias: daily maximumtemperature, $25.34^{\circ} \mathrm{C}$; total solar radiation, $18.25 \mathrm{MJ} / \mathrm{m}^{2}$; average wind speed from 0500 to $1200 \mathrm{JST}$, $1.5 .2 .5 \mathrm{~m} / \mathrm{s}$ (MOE, 2012).

and daily maximum OX concentration in the Tokyo metropolitan area (Metropolis of Tokyo, Saitama, Tochigi and Gumma Prefectures).

Annual changes in percentile values for OX concentrations were analyzed by using daily data from July and August for each year to eliminate meteoro- logical bias as follows:

- Daily maximum temperature: $25-34^{\circ} \mathrm{C}$

- Total solar radiation: $18-25 \mathrm{MJ} / \mathrm{m}^{2}$

- Average wind speed from 0500 to 1200 JST: 1.5$2.5 \mathrm{~m} / \mathrm{s}$ 
The numbers of days selected in 2000 to 2010 were $10,9,7,4,8,8,8,10,14,6$, and 11, respectively. Fig. 12 shows percentile values for OX concentrations in the TMA from 2000 to 2010 (MOE, 2012).

Geographically, Tochigi Prefecture is in the northern part of the TMA, Saitama Prefecture is in the middle of the TMA, and the metropolis of Tokyo is in the southern part of the TMA. In general, sea breezes move OX into the northern inland areas of the TMA (Wakamatsu et al., 1996, 1990, 1983).

Analysis of air pollution trends suggested a change in the mechanism of formation of photochemical ozone during the summer in the TMA. Wakamatsu et al. (1999) analyzed the relationship between the concentration of photochemical ozone and emissions of its precursor $\mathrm{NO}_{\mathrm{x}}$ and hydrocarbons in the Kanto area (Tokyo and surrounding prefectures). From 1978 to 1990 , the $\mathrm{NO}_{\mathrm{x}}$ concentration increased, while the $\mathrm{NMHC} / \mathrm{NO}_{\mathrm{x}}$ ratio and NMHC concentration decreased. These changes altered where the maximum ozone concentration occurred in the Kanto area. To clarify the temporal and areal distributions of photochemical air pollution in the Kanto area, the urban airshed model (UAM) of Wakamatsu and Schere (1991) was applied. Assuming a 25\% decrease in NMHC emission intensity and a $50 \%$ increase in $\mathrm{NO}_{\mathrm{x}}$ emission intensity, the UAM simulation yielded almost the same maximum $\mathrm{O}_{3}$ value as that obtained for the base-case simulation for 1981. However, the time of maximum $\mathrm{O}_{3}$ concentration shifted from 1400 JST to 1600 JST. High concentrations of $\mathrm{OX}$ were usually observed near the shore in the morning, and moved inland following sea breezes. Under these meteorological conditions, the time shift obtained from the UAM simulation corresponds to the observed areal shift of the daily maximum $\mathrm{O}_{3}$ concentration. Since 1990, the annual mean concentration of $\mathrm{NO}_{\mathrm{x}}$ in the metropolis of Tokyo has been decreasing, and the annual maximum OX concentration has been increasing. In contrast, after 2000, the decreasing gradient in $\mathrm{NO}_{2}$ concentration increased, and the OX maximum concentration showed a decreasing trend (Figs. 9 and 10). After 2006, the year VOC regulations were implemented in Japan, the decreases in high-percentile OX concentrations became clearer (Fig. 12).

\subsubsection{Impact of Regulations on Levels of SPM and $\mathrm{PM}_{2.5}$ in Air}

The history and impact of regulations focused on reducing SPM levels in Tokyo are shown in Fig. 13. From 1980 to 1990, SPM concentrations increased. After promulgation of the Automobile $\mathrm{NO}_{\mathrm{x}} \mathrm{Law}$ in 1992 , the $98^{\text {th }}$ percentile values of the SPM concentrations in Tokyo decreased.

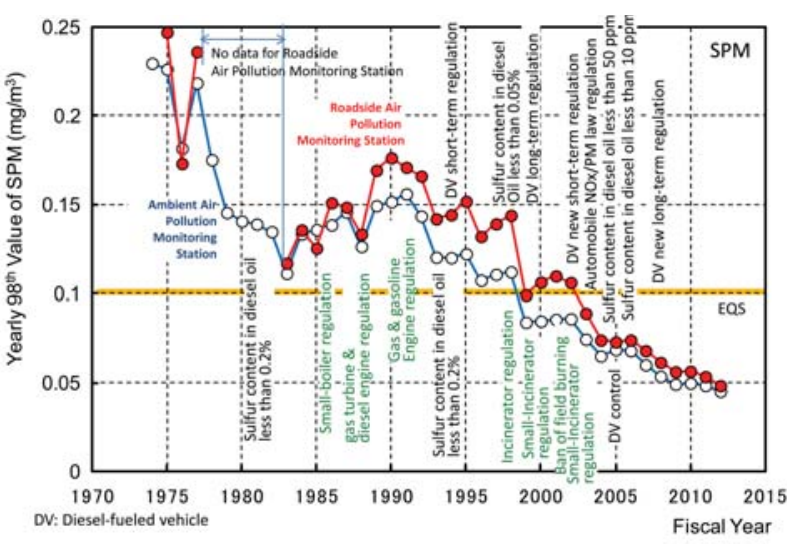

Fig. 13. History and impact of regulations focused on reducing the SPM concentration in Tokyo. Trends for the yearly $98^{\text {th }}$ percentile values of the SPM concentrations are shown.

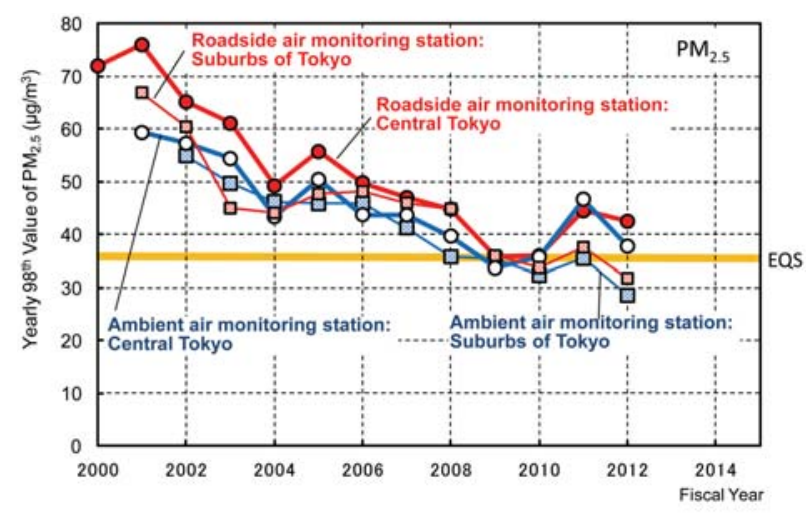

Fig. 14. Trends for yearly $98^{\text {th }}$ percentile values of the $\mathrm{PM}_{2.5}$ concentrations in Tokyo.

In 1999 , the $98^{\text {th }}$ percentile value of the SPM concentration decreased significantly, mainly due to the meteorological conditions of 1999 and the shutdown of a small incinerator (concerns about dioxins led to the shutdown of the incinerator). After promulgation of the Automobile $\mathrm{NO}_{\mathrm{x}} / \mathrm{PM}$ Law in 2001, the quality of the air along roadsides improved, and after 2005, the SPM concentrations measured at ambient air-monitoring stations were not much different from those measured at roadside air-monitoring stations.

Fig. 14 shows trends for the yearly $98^{\text {th }}$ percentile values of the $\mathrm{PM}_{2.5}$ concentrations in Tokyo. $\mathrm{PM}_{2.5}$ concentrations have decreased since 2000 , but are still above the EQS. The $\mathrm{PM}_{2.5}$ concentrations were similar at roadside and ambient air-monitoring stations during the period 2000-2012.

\section{3 Summary and Future Challenges}

We analyzed air pollution trends in Japan, both 
nationwide and in the Tokyo metropolitan area, for the period between 1970 and 2012, and evaluated the impact of countermeasures against urban air pollution. Our analysis showed the following:

CO: In 1975, the average concentrations of CO at roadside air-monitoring stations were almost double those at ambient air-monitoring stations, but in 2011, the concentrations of $\mathrm{CO}$ at roadside and ambient air-monitoring stations were almost the same. In 2011 and 2012, the EQS for CO was satisfied at all stations monitoring $\mathrm{CO}$ concentration.

$\mathrm{SO}_{2}: \mathrm{SO}_{2}$ from mobile sources used to be mainly due to sulfur in diesel fuel, but the sulfur content in diesel fuel was reduced on several occasions, and the $\mathrm{SO}_{2}$ concentration along roads and in the general environment has declined. In 2011 and 2012, the EQS for $\mathrm{SO}_{2}$ was satisfied at most stations monitoring $\mathrm{SO}_{2}$ concentration, but occasionally, $\mathrm{SO}_{2}$ emissions from volcanoes caused the $\mathrm{SO}_{2}$ concentration to rise.

$\mathrm{NO}_{2}$ : $\mathrm{NO}$ is mainly formed from atmospheric nitrogen during combustion of fuel. NO is converted into $\mathrm{NO}_{2}$ in the atmosphere, and mitigating $\mathrm{NO}$ pollution is difficult. $\mathrm{NO}_{2}$ concentrations decreased from 1970 to 1985 , but increased from 1985 to 1995 . After $1995, \mathrm{NO}_{2}$ concentrations decreased, especially after 2006, when they dropped remarkably. In 2011 and 2012, the EQS for $\mathrm{NO}_{2}$ was satisfied at most stations monitoring $\mathrm{NO}_{2}$ concentration, except roadside stations.

OX: From 1980 to 2010, the annual mean of the daily maximum OX concentrations increased. After 2006, the concentrations of the $98^{\text {th }}$ percentile values of the OX concentrations decreased. In 2011 and 2012, the EQS for OX was not satisfied at most stations monitoring OX concentrations.

NMHC: NMHC concentrations have been decreasing. In 2010, the NMHC concentrations at roadside and ambient air-monitoring stations were almost the same.

PM: The environmental concentration of SPM has been falling in recent years. In 2011, the EQS for SPM was satisfied at $69.2 \%$ of ambient air-monitoring stations and $72.9 \%$ of roadside air-monitoring stations. Mineral dust from continental Asia often affects wide-area SPM air pollution in Japan. The impacts are especially pronounced in the western part of Japan in the spring, and year-round variation is large. The environmental concentration of $\mathrm{PM}_{2.5}$ has fallen in recent years, but still exceeds the EQS.

Air pollution trends are closely connected to econo- mic activity and implementation of regulations. The following is a list of important laws and major events affecting trends in air pollution.

1967: Basic Law for Environmental Pollution Control

1968: Air Pollution Control Law

1971: Creation of Environment Agency

1973: EQSs for CO, $\mathrm{SO}_{2}, \mathrm{NO}_{2}, \mathrm{OX}$, and SPM

1974: A total pollution load regulation system for $\mathrm{SO}_{\mathrm{x}}$ 1981: A total pollution load regulation system for $\mathrm{NO}_{\mathrm{x}}$ 1986-1991: Bubble boom

1992: Automobile $\mathrm{NO}_{\mathrm{x}}$ Law

1999: Dioxin issue

2001: Automobile $\mathrm{NO}_{\mathrm{x}} / \mathrm{PM}$ Law

2003: Diesel vehicle regulation (Tokyo, Chiba, Saitama, and Kanagawa Prefectures)

2006: VOCs regulation

2007: $\mathrm{NO}_{\mathrm{x}} / \mathrm{PM}$ Law was amended

2008: Lehman shock

2009: EQS for $\mathrm{PM}_{2.5}$

The annual average concentrations of $\mathrm{CO}, \mathrm{SO}_{2}$, and NMHC decreased monotonically from 1970 to 2012. The annual average $\mathrm{NO}_{2}$ and SPM concentrations increased during the Bubble boom period (1986-1991), especially in the Tokyo area, and decreased after 1995. Annual average OX concentrations have been increasing since 2000 , but the annual maximum values have decreased since 2006. In general, the annual average concentrations of primary air pollutants have been decreasing. In the summer of 1970 , damage to humans and plants by photochemical air pollution in the Tokyo metropolitan area was reported for the first time. Since then, secondary gaseous and particulate air pollution has been an important environmental issue. Improving regional and global air quality will require international cooperation and a deeper understanding of the formation and fate of atmospheric air pollutants, and the following studies and cooperative efforts should be carried out.

\section{3.1 Air Pollution Monitoring and Analysis}

Air quality monitoring stations should continue to collect continuous hourly data on primary air pollutant levels. Such data are useful for deciding when to issue official air pollution warnings and declare air pollution emergencies; for evaluating the efficacy of air quality standards in limiting air pollution; for understanding mechanisms of formation of secondary air pollutants; for determining the impact of regulations on controlling air pollution; and for identifying trends in air pollutant levels. Long-term trend analysis must take into account changes in sampling methods, monitoring methods, and calibration proce- 
dures due to advancing technology. Three-dimensional information is necessary to analyze the horizontal and vertical distributions of air pollutants. Remotesensing and -sounding data for meteorological elements and pollutants will be useful for trend analysis. To understand fate and transport of pollutants in the atmosphere, wide-area data analysis should be conducted. Chemical species in $\mathrm{PM}_{2.5}$ should be identified and quantified, which is especially important in understanding the relationship between emissions of air pollutants and the environmental concentration of $\mathrm{PM}_{2.5}$.

\subsection{Modeling and emission survey}

Secondary air pollutants are formed through complex, nonlinear chemical reactions. Meteorological parameters also play an important role. To understand the formation and fate of these pollutants in the atmosphere, a three-dimensional air pollution modeling study should be undertaken. The model must be validated periodically with actual three-dimensional air pollution and meteorological data.

Studies to precisely identify anthropogenic and biogenic sources of air pollutants should be continuously carried out. Changes in the chemical composition of $\mathrm{PM}_{2.5}$ (i.e., the proportions of organic, inorganic, carbonaceous, and elemental components) over time will be especially useful for evaluating the effect of air pollution countermeasures on trends in source-receptor relationships.

\subsubsection{International cooperation}

Transboundary air pollution has become an important issue, especially for ozone and $\mathrm{PM}_{2.5}$, underscoring the importance of areal representativeness and coverage of monitoring stations. In 2012, the Japan Society for Atmospheric Environment became an incorporated body of the Public Utility Association. International cooperation and cooperation between the academic, government, and private sectors will be required to improve regional and global atmospheric environmental conditions.

\section{ACKNOWLEDGEMENT}

This work was partly supported by the JST/JICA SATREPS (Science and Technology Research Partnership for Sustainable Development) under the project "Joint Research Project on Formation Mechanism of Ozone, VOCs, and $\mathrm{PM}_{2.5}$ and Proposal of Countermeasure Scenario."

\section{REFERENCES}

MOE (Ministry of Environment, Japan). (2012) Survey report for photochemical air pollution: Focusing on future survey and research, 1-180 (in Japanese).

Wakamatsu, S., Ogawa, Y., Murano, K., Goi, K., Aburamoto, Y. (1983) Aircraft survey of the secondary photochemical pollutants covering the Tokyo metropolitan area. Atmospheric Environment 17, 827-835.

Wakamatsu, S., Uno, I., Suzuki, M. (1990) A field study of photochemical smog formation under stagnant meteorological conditions. Atmospheric Environment 24A, 1037-1050.

Wakamatsu, S., Schere, K.L. (1991) A study using a three dimensional photochemical smog formation model under conditions of complex flow: Application of the Urban Airshed Model to the Tokyo metropolitan area. US EPA Report, EPA/600/S3-91/015, 1-84.

Wakamatsu, S., Ohara, T., Uno, I. (1996) Recent trends in precursor concentrations and oxidant distribution in the Tokyo and Osaka areas. Atmospheric Environment 30, 715-721.

Wakamatsu, S., Uno, I., Ohara, T., Schere, K.L. (1999) A study of the relationship between photochemical ozone and its precursor emissions of nitrogen oxides and hydrocarbons in the Tokyo area. Atmospheric Environment 33, 3097-3108.

Wakamatsu, S. (2005) Japanese countermeasures against urban air pollution. The 5th Korea/China/Japan Tripartite Joint Environmental Training, National Institute of Environmental Research, Ministry of Environment, Republic of Korea, November 20-26, 2005, Inchon, Republic of Korea, 33-47. accepted 5 December 2013) 